\title{
Effects of early intracoronary streptokinase on infarct size estimated from cumulative enzyme release and on enzyme release rate: $A$ randomized trial of 533 patients with acute myocardial infarction*
}

The effects of early intracoronary streptokinase (SK) on enzymatic infarct size and rate of enzyme release were studied in a randomized multicenter trial. A total of 533 patients with acute myocardial infarction (AMI) were allocated to either the SK treatment group $(n=269)$ or the conventional (control) treatment group $(n=264)$. Enzymatic infarct size was represented by the cumulative quantity of $\alpha$-hydroxybutyrate dehydrogenase (HBDH) released by the heart per liter of plasma in the first 72 hours. Rate of enzyme release was represented by the ratio of HBDH quantities released in 24 hours and 72 hours. On an 'intention to treat"' basis, the SK group had a smaller (by $30 \% ; p=0.0001$ ) median enzymatic infarct size and a higher (by $35 \% ; p=0.0001$ ) median rate of enzyme release than the control group. Limitation of infarct size was less apparent in patients treated with intracoronary SK only $(25 \%)$ than in patients treated with intravenous plus intracoronary SK (34\%). Compared to the control group, the enzyme release rate in patients treated with intracoronary SK only was slightly less $(34 \%)$ than that in patients treated with intravenous plus intracoronary SK $(38 \%)$. Patients with a patent infarct-related coronary artery at acute anglography had a median infarct size which was $55 \%(p=0.0001)$ smaller than the median infarct size of the control group, and the median rate of enzyme release was $38 \%(p=0.001)$ higher than the median release rate of the control group. Patients with successful recanalization during intracoronary SK infusion had a median infarct size which was $31 \%(p=0.002)$ smaller than the median infarct size of the control group and a median rate of enzyme release which was $42 \%(p=0.0001)$ higher than the median release rate of the control group. Patients with persistent coronary occlusion in spite of thrombolytic therapy had a median infarct size which was $11 \%$ (NS) higher than the medlan Infarct size of the control group, although the median rate of enzyme release was still $23 \%(p=0.02)$ higher than the median release rate of the control group. It is concluded that thrombolysis in the early phase of AMI limits infarct size and that intracoronary SK treatment itself accelerates the process of enzyme release from infarcted myocardium, independent of the angiographic result. (AM HEART J $1986 ; 112: 672$.

A. van der Laarse, F. Vermeer, ${ }^{1}$ W. T. Hermens, ${ }^{2}$ G. M. Willems, ${ }^{2}$ K. de Neef, ${ }^{1,3}$ M. L. Simoons, ${ }^{1}$ P. W. Serruys, ${ }^{1}$ J. Res,${ }^{4}$ F. W. A. Verheugt, ${ }^{4}$ X. H. Krauss, ${ }^{5}$ F. Bär, ${ }^{6}$ C. de Zwaan, ${ }^{6}$ and J. Lubsen ${ }^{1}$. Leiden, The Netherlands Working group on thrombolytic therapy in acute myocardial infarction of the Netherlands Interuniversity Cardiology Institute.

From the Laboratory of Cardiobiochemistry, University Hospital Leiden, Leiden; and 'Thoraxcenter, Erasmus University and Hospital Dijkzigt, Rotterdam; ${ }^{2}$ Dept. of Biophysics, Biomedical Center, University of Limburg, Maastricht; ${ }^{3}$ Present address:Organon-International BV, OSS; ${ }^{4}$ Dept. of Cardiology, Free University, Amsterdam; 'Dept. of Cardiology, Zuiderziekenhuis, Rotterdam; 'Dept. of Cardiology, St. Annadal Hospital, Maastricht.

Received for publication Feb. 3, 1986; accepted March 21, 1986

Reprint requests: Dr. A van der Laarse, Department of Cardiology, University Ilospital Leiden, gebouw 1, C5-024, Rijnsburgerweg 10, 2333 AA Leiden, The Netherlands.

* Participating centers and collaborators: Thnraxcenter, Erasmus Universi- ty and University Hospital Dijkzigt, Rotterdam (M. v/d Brand, P. de Feyter, P. Fioretti, P. G. Hugenholtz, P. W. Serruys, M. L. Simoons, W. Wijns); Department of Cardiology, Free University, Amsterdam (M. van Eenige, J. Res, J. Roos, F. Visser, F. W. A. Verheugt, E. E. v/d Wall); Department of Cardiology, Zuiderziekenhuis, Rotterdam (D. van Hoogenhuyze, X. H. Krauss, W. J. Remme, C. J. Storm, H. A. C. M. Kruyssen); Department of Cardiology, St. Annadal Hospital, Maastricht (F. Bär, S. Braat, P. Brugada, K. den Dulk, W. T. Hermens, M. Ramentol, H. J. J. Wellens, G. M. Willems, C. de Zwaan); Department of Cardiology, University Hospital, Leiden (B. Buis, J. Engbers, A. v/d Laarse); Data processing center, Thoraxcenter, Erasmus Unjversity Rotterdam (S. v/d Does, R. van Domburg, J. Lubsen, J. P. van Mantgem, K. de Neef, J. Planellas, F. Vermeer, A. Wagenaar, I. Zorn). 
Both short- and long-term prognosis of patients who have had a myocardial infarction depends largely on "infarct size," or rather on the remaining functioning myocardial tissue. ${ }^{1.4}$ Thus it is likely that limitation of "infarct size" will lead to a better prognosis of infarct patients. Early recanalization of the occluded coronary artery in patients with acute myocardial infarction (AMI) has been proposed as a method for myocardial salvage. ${ }^{5.6}$ We recently completed a study of 533 patients comparing early recanalization by intracoronary administration of streptokinase (SK) with conventional treatment. The results indicate that early recanalization does indeed limit "infarct size" (estimated from serial enzyme determinations), thereby preserving myocardial function (estimated by contrast angiography and radionuclide angiography). Finally, the 1-year survival rate in patients allocated to thrombolytic therapy was significantly improved compared to that of patients in the control group $(91 \%$ vs $84 \%))^{7.9}$

This report further details the effects of thrombolytic therapy on the estimated "infarct size" by calculation of total $\alpha$-hydroxybutyrate dehydrogenase (HBDH) enzyme release and the effects of treatment on the rate of enzyme release. Limitation of infarct size was only apparent in patients with a patent infarct-related artery after the intervention. However, in contrast with earlier reports,,$^{10-13}$ the rate of enzyme release appeared to be accelerated by thrombolytic therapy independent of the angiographic results.

\section{METHODS}

Patient selection. The study, sponsored by the Netherlands Interuniversity Cardiology Institute, was initiated in one hospital in 1981 and later extended to tive hospitals. ${ }^{\text {. }}$ 9.14 All patients admitted to the participating coronary care units were eligible for the trial if severe chest pain lasting more than 20 minutes was accompanied by ST segment elevation of $0.2 \mathrm{mV}$ or greater in one or more precordial leads and/or $0.1 \mathrm{mV}$ or greater in one or more limb leads. In addition, patients were included who had $0.2 \mathrm{mV}$ ST segment depression in precordial leads indicative of posterior wall infarction. Patients up to the age of 70 years were included if they were admitted to the coronary care unit within four hours after the onset of symptoms. Exclusion criteria were: previous treatment with SK, bypass surgery of the infarct-related vessel, recent trauma, traumatic resuscitation, gastrointestinal bleeding, gastric or duodenal ulcer, hematuria or cerebrovascular accident within 3 months, pregnancy or menstruation, or inability to give informed consent.

Eligible patients were registered by a telephone answering service which then provided treatment allocation. After randomization, informed consent was requested from patients allocated to the group receiving thrombolytic therapy only ${ }^{15}$ Prior to cardiac catheterization patients received nitroglycerin, lidocaine $(2 \mathrm{mg} / \mathrm{min})$, heparin $(5000 \mathrm{U})$, acetylsalicylic acid $(250 \mathrm{mg})$, and prednisolone $(100 \mathrm{mg})$ intravenously. Coronary arteriography was performed with preformed catheters from the femoral approach. If the infarct-related artery appeared occluded, SK was administered intracoronarily at the rate of 4000 $\mathrm{U} / \mathrm{min}$ until all visible clots disappeared. Usually 250,000 $\mathrm{U}$ was given. In patients with persistent occlusion, subsel ective infusion or mechanical perforation of the thrombus was attempted on occasion, while percutaneous transluminal coronary angioplasty was performed in some of the patients with severe residual stenosis of the infarctrelated coronary artery. ${ }^{16}$ In order to reduce treatment delay, in patients admitted since January, 1984, 500,000 U of SK was administered intravenously, immediately after informed consent was obtained, as soon as possible, followed by intracoronary SK infusion during acute cardiac catheterization.?

Measurement of serum enzyme activities. Samples of $5 \mathrm{ml}$ of venous blood were obtained at admission, directly after the SK infusion procedure (if allocated to study treatment), every 12 hours for the first 2 days, and daily for the following 3 days. The blood samples were allowed to clot, and the activities of HBDH in the serum were measured in the coronary care units of Rotterdam Thoraxcenter, Maastricht St. Annadal Hospital, and the University Hospital Leiden, and the activity of lactate dehydrogenase (LDH) in the serum was measured in the Rotterdam Zuiderziekenhuis and the Amsterdam Free University Hospital. Because erythrocytes contain high activity levels of $\mathrm{LDH}-1$ and $\mathrm{LDH}-2$, hemolytic samples were discarded, and new samples were ordered.

A.ctivity levels are expressed in micromoles of $\alpha$-ketobutyrate converted ( $\mathrm{HBDH})$ or micromoles of pyruvate converted (LHD) per minute or liter of serum at $37^{\circ} \mathrm{C}$. The autoanalyzers which measured $\mathrm{HBDH}$ activities were calibrated daily such that the HBDH activity of a test serum (Autonorm H, batch 227, Nyegaard \& Co, Oslo, Norway) equaled $430 \mathrm{U} / \mathrm{L}$. So calibrated, the mean reference value of $\mathrm{HBDH}$ activity in serum is $83 \mathrm{U} / \mathrm{L}$. From the autoanalyzers, which measured LDH activities, the serum $\mathrm{LDH}$ activities were converted to $\mathrm{HBDH}$ activities via the following formulas: Amsterdam Free University Hospital $\mathrm{HBDH}=1.106 \times \mathrm{LDH}+16 \quad(r=0.96)$, and Rotterdam Zuiderziekenhuis $\mathrm{HBDH}=0.473 \times \mathrm{I}$. DH $-5 \quad(r=0.99)$. These formulas were obtained after $\mathrm{LDH}$ and $\mathrm{HBDH}$ measurement of 10 dilutions of an infarct serum diluted with a pasteurized plasma protein solution (Central Laboratory of the Netherlands Red Cross Blood Transfusion Service, Amsterdam, the Netherlands) spanning an LDH range of 0 to $2660 \mathrm{U} / \mathrm{L}$.

Calculation of cumulative HBDH release. Previously the two-compartment model was presented ${ }^{17}$ with which the movements of liberated myocardial proteins to and from intravascular and extravascular spaces can be described. This model has now been verified for a great number of proteins, mostly enzymes. Brietly, this model 
Table I. Median values (M) and first and third quartiles $(\mathrm{Q} 1, \mathrm{Q3})$ of calculated and estimated cumulative HBDH release of patients allocated to thrombolytic therapy and to conventional treatment (control subjects) groups

\begin{tabular}{|c|c|c|c|c|c|c|c|c|c|}
\hline \multirow[b]{2}{*}{ Patients } & \multirow[b]{2}{*}{$n$} & \multicolumn{4}{|c|}{ Streptokinase } & \multicolumn{2}{|c|}{ Control } & \multirow[b]{2}{*}{$Q_{3}$} & \multirow[b]{2}{*}{$\mathrm{p}^{*}$} \\
\hline & & $M$ & $Q_{1}$ & $Q_{3}$ & $n$ & $M$ & $Q_{i}$ & & \\
\hline 448 patients with HBDHQ72 calculated $\dagger$ & 230 & 770 & 450 & 1230 & 218 & 1020 & 580 & 1630 & 0.0001 \\
\hline $\begin{array}{l}495 \text { patients with HBDHQ72 calculated } \\
\text { (448) or estimated including } 17 \text { patients } \\
\text { without AMI (Q72=40 U/L) and } 30 \\
\text { patients who died early }(8 \mathrm{SK}, 22 \\
\text { control, Q72 }=6000 \mathrm{U} / \mathrm{L}) \ddagger\end{array}$ & 248 & 770 & 410 & 1260 & 247 & 1100 & 580 & 1860 & 0.0001 \\
\hline $\begin{array}{l}29 \text { patients with Q72 estimated by } \\
1.2 \times \mathrm{Q} 48\end{array}$ & 14 & 860 & 600 & 1500 & 15 & 1290 & 910 & 1850 & 0.0001 \\
\hline $\begin{array}{l}9 \text { patients with } Q 72 \text { estimated from } \\
\text { CK(MB) curves }\end{array}$ & 7 & 400 & 200 & 500 & 2 & - & 1050 & 1250 & 0.0001 \\
\hline All 533 patients with Q72§ & 269 & 760 & 400 & 1250 & 264 & 1140 & 630 & 1860 & 0.0001 \\
\hline
\end{tabular}

*Mann-Whitney test.

†Indicated by HBDHQ72.

†Indicated by HBDHQ72A.

SIndicated by HBDHQ72B.

AMI = acute myocardial infarction.

enables the calculation of the total quantity of enzyme which has entered the plasma up to time $t(Q[t])$ per liter of plasma. If the release of enzymes into plasma starts at time $t=0, Q(t)$ equals the quantity of enzyme present in 1 $L$ of plasma $\left(C_{p}[t]\right)$ plus the quantity of enzyme present in the extravascular compartment per liter of plasma $\left(\mathrm{C}_{e}[\mathrm{t}]\right)$ plus the quantity of enzyme that has been eliminated from $1 \mathrm{~L}$ of plasma up to time $\mathrm{t}$. Cumulative release of enzyme per liter of plasma up to time $t, Q(t)$, is represented by: $\mathrm{Q}(\mathrm{t})=\mathrm{C}_{\mathrm{p}}^{\prime}(\mathrm{t})+\mathrm{C}_{\mathrm{e}}^{\prime}(\mathrm{t})+\mathrm{FCR} \int_{0}^{\mathrm{t}} \mathrm{C}_{\mathrm{p}}^{\prime}(\tau) \mathrm{d} \tau$ (equation 1$)$, in which FCR is the fractional catabolic rate constant, and $C_{p}^{\prime}(t)$ and $C^{\prime}(t)$ are the enzyme concentrations at time $t$ in plasma and the extravascular space, respectively. The accents added to $\mathrm{C}^{\prime}{ }_{\mathrm{p}}(\mathrm{t})$ and $\mathrm{C}^{\prime}{ }_{\mathrm{e}}(\mathrm{t})$ in equation 1 indicate that enzyme concentrations are corrected for the normal steady-state concentration $\left(\mathrm{C}_{\mathrm{s}}\right)$, that is, $\mathrm{C}_{\mathrm{p}}^{\prime}(\mathrm{t})=$ $\mathrm{C}_{\mathrm{p}}(\mathrm{t})-\mathrm{C}_{\mathrm{s}}$.

This implies that $Q(t)$ does not include normal steadystate release of enzyme but only refers to the extra release of enzyme resulting from AMI. The term $\mathrm{C}^{\prime}(\mathrm{t})$ can be calculated according to the formula: $C^{\prime}{ }_{e}(t)=$ TER

$e^{(-E R R \cdot t)} \cdot \int_{0}^{t} e^{(E R R \cdot \tau)} \cdot C^{\prime}{ }_{p}(\tau) d \tau$ (equation 2), in which

TER and ERR represent the transcapillary escape rate constant and the extravascular return rate constant, respectively..$^{18}$ With the use of fixed mean values for FCR, TER, and ERR being $0.015 \mathrm{hr}^{-1}, 0.014 \mathrm{hr}^{-1}$, and $0.018 \mathrm{hr}^{-1}$, respectively, $Q(t)$ was calculated from serial determinations of serum HBDH activities and the normal steadystate $\mathrm{HBDH}$ activity $\mathrm{C}_{\mathrm{s}}=83 \mathrm{U} / \mathrm{L}$. The total $\mathrm{HBDH}$ activity ultimately released by the infarcted myocardium is represented by HBDHQ72 as at 72 hours after onset of chest pain enzyme release rate is almost $(\geqslant 95 \%)$ completed by then. ${ }^{18}$

Calculation of $\mathrm{HBDH}$ release rate. As a measure of the rate with which enzymes are liberated from the myocardium into the circulation, the ratio HBDHQ24/HBDHQ72 is used, that is, the ratio of the quantities released in the first 24 hours and the first 72 hours.

Statistical analysis. Differences between medians of two groups of data were tested with the Mann-Whitney rank-sum test. Differences with $p$ values $>0.05$ (twosided) were considered not significant.

\section{RESULTS}

Between June, 1981, and March, 1985, a total of 533 patients were entered into the study. Two hundred sixty-four patients were allocated to the conventional treatment group and 269 patients to the thrombolytic therapy group. In spite of treatment allocation, no angiography was performed in 35 patients. $^{7,8}$ In 111 of 136 patients catheterized without intravenous SK the infarct-related vessel was occluded ( $82 \%)$ and recanalization was achieved in $79 \%$ of these. After prior intravenous SK the infarct-related vessel was patent in 40 of 98 patients (41\%). Ultimately the infarct-related artery was patent at admission or recanalized in 198 patients $(85 \%)$. The median time between onset of symptoms and angiographic documentation of a patent infarct-related vessel was 200 minutes.

of 533 patients included in the study, measurements of $\mathrm{HBDH}$ (or LDH) were complete in 448 patients $(84 \%)$. The measurements were incomplete in 85 patients. In order to verify whether the results 
would be affected by missing data, HBDHQ72 was estimated from other data which were available for these 85 patients. Data were missing from 17 patients who did not develop an infarct in spite of prolonged chest pain and significant ST segment elevation at admission. In these 17 patients creatine kinase (CK), CK-MB, HBDH, and other enzymes remained within reference ranges. Furthermore, data were necessarily incomplete in 30 patients who died early (within 72 hours) from large infarctions, characterized by pulmonary edema, cardiogenic shock, and a rapid rise of plasma enzymes to high levels. In the present analysis these patients were entered with values for HBDHQ72 which were arbitrarily set at 40 (for patients without infarct) and 6000 (for patients who died within 72 hours), respectively. The figures 40 and $6000 \mathrm{U} / \mathrm{L}$ corresponded to the lowest and the highest values of the 448 calculated infarct sizes. In 29 patients inadequate blood sampling prevented direct calculation of infarct size; however, HBDHQ72 could be approximated by multiplication of calculated HBDHQ48 by a factor of 1.2 . This factor 1.2 was chosen because it was the value of the HBDHQ72/HBDHQ48 ratio in 218 control patients. Although in the patients allocated to the thrombolytic therapy group the mean ratio of HBDHQ72/HBDHQ48 was about 1.1, the factor 1.2 was used in all 29 patients in whom HBDHQ48 was present and HBDHQ72 was absent. Thus probably a small overestimation of infarct size was introduced in 14 patients allocated to the SK treatment group. In the nine patients in whom HBDHQ48 could not be calculated, HBDHQ72 was estimated via comparison of serum CK(MB) curves with serum CK(MB) curves of patients with calculated HBDHQ72.

The data presented in Table I show that the median infarct size estimated from HBDHQ72 was $25 \%$ lower in patients allocated to thrombolysis than in control patients. This difference in HBDHQ72 was hardly affected by the addition of the estimated data to the actual measurements: in fact, inclusion of estimated infarct sizes (HBDHQ72A and HBDHQ72B) increased these differences to $30 \%$ and $33 \%$, respectively. These differences were similar among the five participating hospitals. Further analysis is based on both actual HBDH measurements (448 patients; HBDHQ72) and on data including patients without infarction and those who died early (495 patients; HBDHQ72A). Although much attention has been paid to the standardization of serum enzyme determinations, it appears that median HBDHQ72 values
INFARCT SIZE LIMITATION PER PARTICIPATIN: CENTER

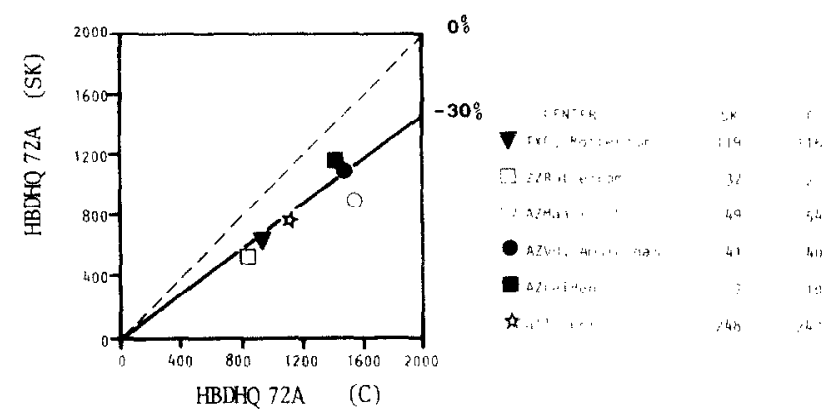

Fig. 1. Median value of enzymatic infarct size (HBDHQ72A) in patients allocated to thrombolytic therapy (SK) is plotted against HBDHQ72A in patients allocated to conventional treatment (C) per participating center. Although an interdepartment variation is obvious, each center shows an almost identical result in terms of infarct size limitations of about $30 \%$

varied per center. This was true for both patient groups (SK and control). Fig. 1 shows the median HBDHQ72A values in both patient groups per center. Although an interdepartment variation is obvious, each center shows an almost identical lower (by $30 \%$ ) HBDHQ72 value in the SK group of patients than in control patients.

Table II shows the medians and quartiles of calculated HBDH release (HBDHQ) after 24, 48, and 72 hours from the onset of infarction in patients in the control and SK groups. Evidently, after 24 hours median HBDHQ values in both patient groups are almost identical, while cumulative HBDH release increases less during the following 2 days in the SK group than in the control group. At 72 hours from the onset of infarction, the median HBDHQ72 value of the SK group is $25 \%$ less than that of the control group $(p=0.0001)$. The difference in the time course of HBDH release between the two groups of patients is the result of a faster release of HBDH in the SK group than in the control group, as is reflected by the median HBDHQ24/HBDHQ72 which is 0.65 and 0.48 in the SK and control group, respectively $(p=0.0001)$.

Table III shows that median HBDHQ72A values differ by $25 \%$ in favor of SK in the first 277 patients and by $34 \%$ in favor of SK in patients pretreated with intravenous SK. The HBDH release rate was $34 \%$ and $38 \%$ higher in the SK group than in the control group for intracoronary SK and intravenous plus intracoronary SK treatment, respectively.

Fig. 2 shows the median values as well as the first and third quartile values of HBDHQ72A and ratio HBDHQ24/HBDHQ72 in patients in the control 
Table II. Median values (M) and first and third quartiles (Q1,Q3) of cumulative quantities of HBDH released per liter of plasma after $24,48,72$, and 96 hours in patients allocated to thrombolytic therapy and to conventional treatment (control subjects) groups

\begin{tabular}{|c|c|c|c|c|c|c|c|c|c|}
\hline & \multirow[b]{2}{*}{$n$} & \multicolumn{2}{|c|}{ Streptokinase } & \multirow[b]{2}{*}{$Q_{3}$} & \multicolumn{4}{|c|}{ Controls } & \multirow[b]{2}{*}{$\mathrm{p}^{*}$} \\
\hline & & $M$ & $Q_{t}$ & & $n$ & $M$ & $Q_{1}$ & $Q_{z}$ & \\
\hline HBDHQ24 & 252 & 460 & 260 & 780 & 236 & 490 & 300 & 730 & NS \\
\hline HBDHQ48 & 245 & 680 & 420 & 1070 & 234 & 920 & 530 & 1390 & 0.003 \\
\hline HBDHQ72 & 230 & 770 & 450 & 1230 & 218 & 1020 & 580 & 1630 & 0.0001 \\
\hline HBDHQ96 & 187 & 780 & 450 & 1280 & 171 & 1050 & 620 & 1750 & 0.0006 \\
\hline HBDHQ24/HBDHQ72 & 230 & 0.65 & 0.55 & 0.76 & 218 & 0.48 & 0.39 & 0.58 & 0.0001 \\
\hline
\end{tabular}

NS = not significant.

*Mann-Whitney rank-sum test (two-sided).

Table III. Median values (M) and first and third quartiles (Q1,Q3) of enzymatic infarct size (HBDHQ72A) and enzyme release rate (HBDHQ24/HBDHQ72) in patients allocated to thrombolytic therapy and to conventional treatment (control subjects)*

\begin{tabular}{|c|c|c|c|c|c|c|c|c|c|}
\hline \multirow{2}{*}{$\begin{array}{l}\text { Infarct size } \\
H B D H Q 72 A\end{array}$} & \multirow[b]{2}{*}{$n$} & \multicolumn{3}{|c|}{ Streptokinase } & \multirow[b]{2}{*}{$n$} & \multicolumn{2}{|c|}{ Control } & \multirow[b]{2}{*}{$Q_{3}$} & \multirow[b]{2}{*}{$\mathrm{p} \dagger$} \\
\hline & & $M$ & $Q_{1}$ & $Q_{3}$ & & $M$ & $Q_{1}$ & & \\
\hline All patients & 248 & 770 & 410 & 1260 & 247 & 1100 & 580 & 1860 & 0.0001 \\
\hline Intracoronary SK & 140 & 750 & 380 & 1220 & 137 & 1000 & 580 & 1700 & 0.001 \\
\hline Intravenous + intracoronary SK & 108 & 810 & 450 & 1320 & 110 & 1220 & 640 & 2010 & 0.001 \\
\hline \multirow{2}{*}{$\begin{array}{c}\text { Enzyme release rate } \\
H B D H Q 24 / H B D H Q 72\end{array}$} & & \multicolumn{3}{|c|}{ Streptokinase } & & \multicolumn{2}{|c|}{ Control } & & \\
\hline & $n$ & $M$ & $Q_{1}$ & $Q_{3}$ & $n$ & $M$ & $Q_{1}$ & $Q_{3}$ & $p \dagger$ \\
\hline All patients & 230 & 0.65 & 0.55 & 0.76 & 218 & 0.48 & 0.39 & 0.58 & 0.0001 \\
\hline Intracoronary SK & 127 & 0.67 & 0.57 & 0.76 & 121 & 0.50 & 0.39 & 0.61 & 0.0001 \\
\hline Intravenous + intracoronary SK & 103 & 0.65 & 0.53 & 0.76 & 97 & 0.47 & 0.40 & 0.54 & 0.0001 \\
\hline
\end{tabular}

*Until 1984, SK was given intracoronarily only, and from January, 1984, on SK was given intravenously followed by intracoronarily.

† Mann-Whitney rank-sum test (two-sided).

and SK groups. In addition, the SK group is subdivided into four groups of patients: those without catheterization ( 35 patients), 65 with a patent infarct-related coronary artery at angiography, 133 patients with actual recanalization by thrombolytic therapy, and 36 patients in whom the artery remained occluded (Fig. 2).

Median infarct sizes of the patients without acute coronary angiography $(910 \mathrm{U} / \mathrm{L})$, as well as those of the patients in whom the infarct-related artery remained occluded (1220 U/L), were not significantly different from those of control patients $(1100$ $\mathrm{U} / \mathrm{L}$ ). In patients with recanalization during angiography median infarct size was $760 \mathrm{U} / \mathrm{L}$, which is $31 \%$ lower than in control patients $(p=0.0001)$. The smallest infarcts were observed in 65 patients who already had a patent infarct-related artery at first angiography (median $500 \mathrm{U} / \mathrm{L}$ ). In Fig. 2 the values of the ratio HBDHQ24/HBDHQ72 are presented, which are a measure of the rate of enzyme release. The control group and the patients in the SK group who did not undergo acute coronary angiography had a relatively low median ratio HBDHQ24/HBDHQ72 (0.48 and 0.55, respectively) compared to patients with patent infarct-related coronary arteries $(0.66)$, those with recanalization during angiography (0.68), and those with persistent occlusion (0.59).

In order to study whether the severity of the remaining stenosis of the infarct-related artery had any effect on infarct size or rate of enzyme release, patients were subdivided according to the visual interpretation of the degree of stenosis after recanalization. The results in Fig. 2 show no effect of the degree of opening of the infarct-related artery on infarct size.

Fig. 3 shows that in both anterior (including anteroseptal infarcts) and inferior (including posterior) infarcts cumulative $\mathrm{HBDH}$ release was lower and $\mathrm{HBDH}$ release rate was higher in patients allocated to SK treatment compared to control patients. When both groups are compared, median values of HBDHQ72A differ by $34 \%(p=0.007)$ and by $31 \%(p=0.002)$ for patients with anterior and 
ENIYMATIC INFARCT SIZE

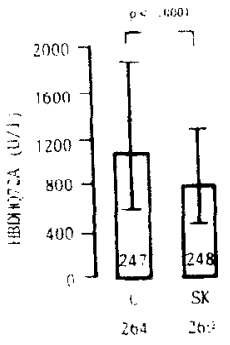

Sk-AI: COATHE PATINTS
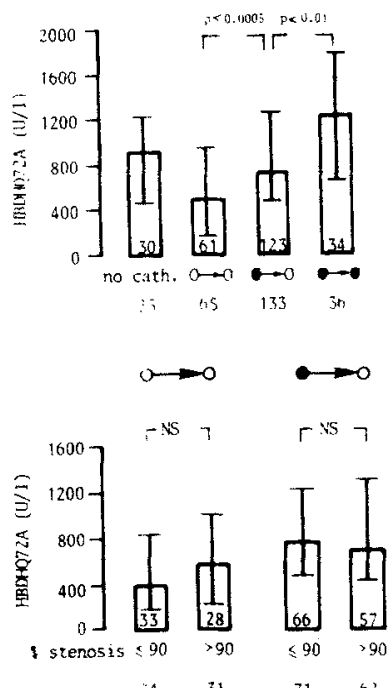

RATE OF ENZMIE RELEASE

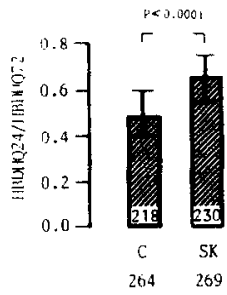

SK-ALLOCATED PATIENTS
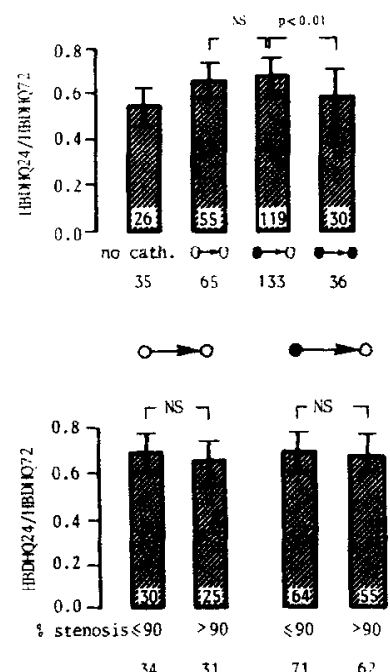

Fig. 2. Median values of enzymatic infarct size (HBDHQ72A) and rate of enzyme release (HBDHQ24/ HBDHQ72) in patients allocated to streptokinase (SK) and control (C) treatment groups, (top), in four categories of patients allocated to $S K$ treatment group (middle), and in four categories of patients with patency of recanalized infarct-related coronary artery (bottom). The number of data per bar is indicated in the bar, and the number of patients per group is indicated below the bar. Levels of first and third quartiles are indicated. Statistical significance of a difference between two medians is calculated by Mann-Whitney rank-sum test (two-sided).

inferior infarcts, respectively. Median values of the HBDHQ24/HBDHQ72 ratio differ by $31 \%$ $(p=0.0001)$ and $38 \%(p=0.0001)$ for patients with anterior and inferior infarcts, respectively.

From a total of 533 patients randomized in the study, $65(12 \%)$ patients have died within 1 year after onset of chest pain: 23 patients allocated to thrombolytic therapy and 42 control patients $(p=0.01)$. In Fig. 4 the number of patients from both groups in four classes of infarct size (HBDHQ72A $\leqslant 600 \mathrm{U} / \mathrm{L}, 601$ to $1200 \mathrm{U} / \mathrm{L}, 1201$ to $1800 \mathrm{U} / \mathrm{L}$, and $>1800 \mathrm{U} / \mathrm{L}$ ) and the number of patients who have died within 1 year after onset of
ENZIMATIC INFARCT SIZE RAIE OR: G, ZMER RELEASE

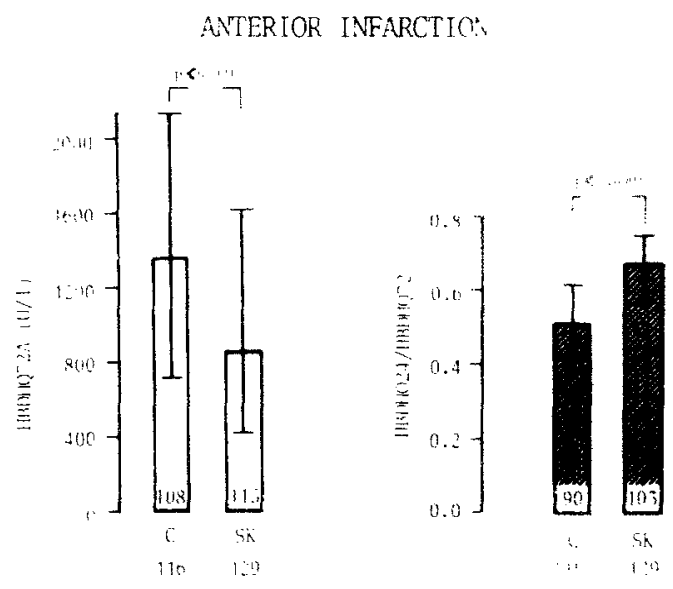

INFERIOR INFARCTION
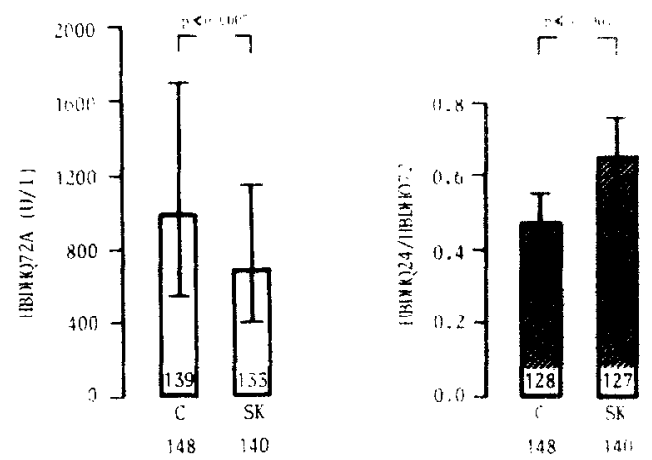

Fig. 3. Median values of enzymatic infarct size (HBDHQ72A) and rate of enzyme release (HBDHQ24/ HBDHQ72) in patients having anterior infarction or inferior infarction allocated to streptokinse $(S K)$ and control $(C)$ treatment groups. The number of data per bar is indicated in the bar, and the number of patients per group is indicated below the bar. Levels of first and third quartiles are indicated. Statistical significance of a difference between two medians is calculated by Mann-Whitney rank-sum test (two-sided).

chest pain and per infarct size class per group are shown. This figure demonstrates that thrombolytic therapy is associated with both limitation of infarct size and an improved survival rate when compared to control patients.

Of the 264 control patients and 269 patients allocated to the SK treatment group, angiographic data before discharge from the hospital were obtained from 125 and 129 patients with first AMI, respectively. Fig. 5 shows that in the SK group the median HBDHQ72 was $800 \mathrm{U} / \mathrm{L}$, which was $33 \%$ lower $(p=0.0001)$ than that in the control group $(1190 \mathrm{U} / \mathrm{L})$. Furthermore, in the SK group median 


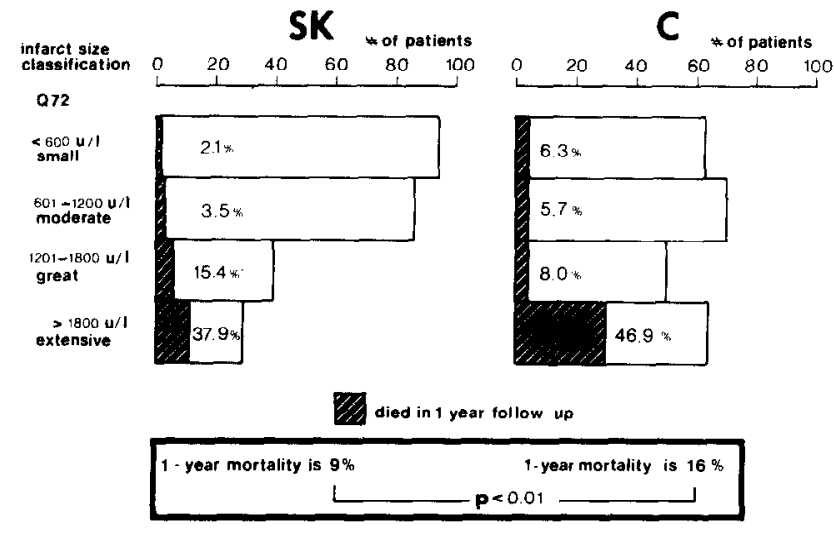

Fig. 4. Mortality rates in four different classes of infarct size in patients allocated to thrombolytic therapy (SK) and in patients allocated to conventional treatment $(C)$ groups.

left ventricular ejection fraction at discharge was 0.57 , which was $14 \%$ higher $(p=0.0005)$ than that in the control group (0.50).

\section{DISCUSSION}

The aim of thrombolytic therapy is rapid restoration of blood flow to the jeopardized myocardium in order to preserve cellular integrity and function or, in other words, "limitation of infarct size." Thus thrombolytic therapy must either prevent the infarction or lead to an infarct with a size smaller than would occur in the absence of thrombolysisinduced reperfusion of the infarct-related coronary artery.

Indirectly, limitation of infarct size by early intracoronary SK infusion has been demonstrated to occur since regional and global left ventricular function as well as the mortality rate were markedly improved in treated patients compared to conventionally treated patients. ${ }^{7-9}$ However, studies designed to investigate direct effects of thrombolytic therapy in terms of infarct size limitation are scarce. Therefore, in the study on thrombolytic therapy conducted by the Netherlands Interuniversity Cardiology Institute, measurement of enzymatic infarct size was incorporated. In 495 of 533 patients (93\%) enrolled in the study quantitative information on infarct size (HBDHQ72A) was obtained. This study demonstrates that early thrombolysis does limit infarct size estimated by myocardial HBDH release. As expected, the smallest median $\mathrm{HBDH}$ infarct size was observed in patients with an open artery at angiography and, to a lesser extent, in patients with an occluded artery which later recanalized. Patients with a persistent occlusion in spite of thrombolytic therapy had the same infarct size as patients in the control group.
IN PATIENTS WITH FIRST AMI :

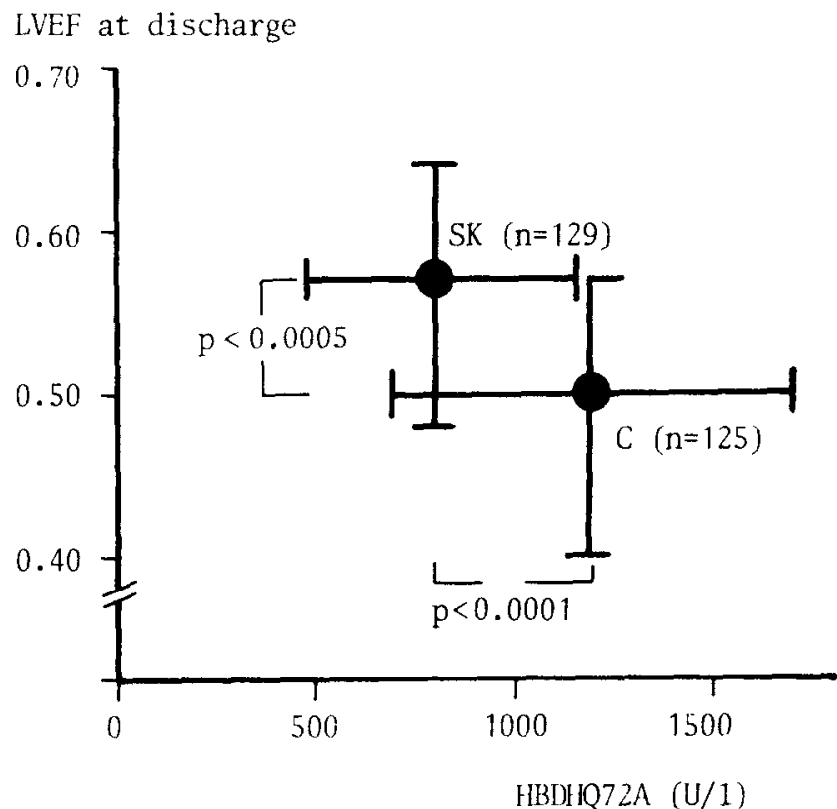

Fig. 5. Relation between left ventricular ejection fraction ( $L V E F)$ determined before discharge from coronary care unit and enzymatic infarct size (HBDHQ72A) in 254 patients with first AMI allocated to streptokinase (SK) or control $(C)$ treatment group. Per treatment group median values and first and third quartiles are presented. Statistical significance of a difference between two medians is calculated by Mann-Whitney rank-sum test (two-sided).

The method used to calculate infarct size in the present study is applicable to several cytoplasmic enzymes liberated from infarcted myocardium. ${ }^{19-22}$ Based on the assumption that different cytoplasmic (iso) enzymes are liberated from necrotic myocytes simultaneously, the different serum (iso)enzyme curves can be fully described by differences in their concentrations in normal myocytes and differences in fractional catabolic rate. Calculation of cumulative released quantities of these (iso)enzymes results in identical overlapping curves when activities are expressed in gram equivalents of myocardium. ${ }^{21}$ Thus the different cytoplasmic (iso)enzymes are released to the same extent percentagewise from the infarcted tissue. In infarcted animal hearts ${ }^{23-25}$ and in infarcted human hearts ${ }^{26}$ the extent to which the infarcted myocardium looses its enzymes is approximately $80 \%$ to $85 \%$.

The two-compartment model employed enables calculation of the cumulative activity released from the infarcted myocardium into the plasma space for each cytoplasmic (iso)enzyme. The method has proved its value for assessing myocardial damage induced by surgical and cardioplegic procedures ${ }^{27-29}$ and for assessing the relationship between enzymat- 
ic infarct size and the occurrence of pump failure, ECG changes, conduction and rhythm disturbances, global left ventricular function, wall motion abnormalities, and 1-year survival rate. ${ }^{17}$ Shell et al ${ }^{30}$ in 1971, published a different method for calculating enzymatic infarct size, which has since then been used by a large number of investigators. This method is confined to CK and CK-MB, and is based on a one-compartment model. As in the early reports they mention a recovery rate of $30 \%$ of the CK (or CK-MB) activity, ${ }^{30}$ and since 1975 only $15 \%,{ }^{31}$ the cumulative CK(-MB) activity calculated on the basis of serial serum CK(-MB) activities has to be multiplied by $1 / 0.3$ (early) or by $1 / 0.15$ (since 1975) to obtain the activity of CK(-MB) released by the heart. The remaining part of the released CK(-MB) is degraded locally in the heart according to the authors. ${ }^{32}$ The factor representing recovery of $\mathrm{CK}$ liberated by necrotic myocytes in the circulation appears to be sensitive to the occurrence of reperfusion of infarcted myocardium. Roberts and Ishikawa $^{33}$ showed that two different relationships exist between accumulated CK release expressed in CK gram-equivalents of infarcted myocardium and anatomic infarct size during unperfused infarction and during infarction followed by early reperfusion. From reperfused myocardium greater CK release per gram of anatomic infarct size has been observed than from unreperfused myocardium.

Tamaki et al., ${ }^{34}$ who also used the method of Shell et al., ${ }^{30}$ observed that in patients with AMI successfully treated with intracoronary urokinase more CK-MB was released per equivalent infarct volume estimated by myocardial emission tomography with thallium-201 than in patients with AMI with unsuccessful thrombolysis. The discrepancies mentioned by these authors may reflect different recovery fractions of the enzyme in both situations, since CK as well as CK-MB are relatively unstable (iso) enzymes compared to aspartate aminotransferase and LDH (see also reference 25). However, the infarct size calculated by the method of Shell et al. ${ }^{30}$ in patients with AMI correlated well with anatomic infarct size in patients who died from AMI, ${ }^{35}$ left ventricular ejection fraction in patients with first AMI ${ }^{36,37}$ and long-term survival rates. ${ }^{1.4,38}$ Erhardt $^{39}$ reported that in 43 patients with AMI the peak serum levels of LDH and heat-stable LDH (representing the combined activities of LDH-1 and LDH2) were well correlated $(r=0.73$ and $r=0.79$, respectively) with anatomic infarct size, measured at postmortem examination. Anderson et al., ${ }^{13}$ who measured serial activities of several (iso)enzymes in serum, calculated the integrated concentrations of serum LDH and serum LDH-1, and did not find significant differences between the SK group and the control group. However, recalculation of released quantities of LDH and LDH-1, by means of the method used in the present study, yielded a smaller infarct size after thrombolysis of $20 \%$ and $40 \%$ with LDH and with LDH-1, respectively. This is in agreement with the better left ventricular ejection fraction after thrombolysis reported by Anderson et al. ${ }^{13}$ Enzyme release rates (Q24/Q72) were 0.49 and 0.77 measured with $\mathrm{LDH}$ and 0.46 and 0.70 measured with LDH-1 for control and SKtreated patients, respectively, which are indeed similar to the results of the present study.

Another advantage of calculation of infarct size from HBDH rather than from CK values is that HBDH-infarct size can be incorporated easily and routinely in trials on infarct size limitation as serum HBDH has to measured only twice a day during the first 2 days and once a day during the following 3 days at low cost. No assumption regarding the $\mathrm{HBDH}$ release function ( $\mathrm{f}[\mathrm{t}]$ ) is incorporated in the calculation. Thus factors which increase (e.g., SK) or decrease (e.g., beta blockers) the HBDH release rate do not influence any parameter involved in the calculation. The quantity of the release as well as the rate at which HBDH is released are the outcome of the calculation, and can be used in rapidly releasing infarcts (reperfusion) as well as in slowly releasing infarcts (unreperfused infarcts) (see also reference 22).

The enzymatic method for quantitating myocardial infarct size has one major drawback since patients must survive the first 3 days to enable calculation of cumulative enzyme release. In order to prevent bias resulting from the higher mortality rate among patients in the control group, we included the patients who died early from extensive infarctions giving those a large value for HBDHQ72. Since this value was chosen arbitrarily nonparametric statistical tests were used. Similarly, patients without infarction were included with a low value for HBDHQ72 (40 U/L).

Enzyme washout, as expressed as the HBDHQ24/ HBDHQ72 release ratio, was increased in all groups of patients after thrombolytic therapy. The latter finding is not completely understood. Shell et al. ${ }^{40}$ demonstrated that reperfusion of the infarcted myocardium significantly augments the release rate of CK-MB, while Ong et al. ${ }^{41}$ reported that in patients with AMI not treated with thrombolytic agents a rapid release rate of CK-MB correlated with improvement of global left ventricular function and regional left ventricular wall motion. These reports suggest that a rapid enzyme release rate is a manifestation of recanalization, either spontaneous or 
induced by thrombolytic therapy. Accordingly several authors advocated the use of the time to peak CK (or CK-MB) as a noninvasive in vitro index to determine the success of reperfusion. ${ }^{10-13}$ However, the present study indicates that one should be very cautious about interpreting a rapid enzyme release rate to be a manifestation of thrombolysis-induced recanalization, since the median rate of $\mathrm{HBDH}$ release in the patients with unsuccessful SK treatment $(0.59)$ was significantly $(p<0.02)$ higher than that in conventionally treated (control) patients (0.48) (Fig. 2). One can speculate on other effects of SK in infarcted hearts besides its thrombolytic action. Fung and Rabkin, ${ }^{42}$ who subjected rabbit hearts to ischemia (low-flow perfusion) plus anoxia (perfusate equilibrated with $95 \%$ nitrogen $+5 \%$ carbon dioxide), found that continuous administration of SK before reperfusion and during reperfusion resulted in a greater recovery of ventricular function than reperfusion alone. Puckett et al. ${ }^{43}$ demonstrated a vasodilatory effect of SK in the nonischemic, isolated rat heart. Furthermore, these authors found less enzyme release during reperfusion of the globally ischemic isolated rat heart in the presence of SK compared to the control ischemic rat heart, suggesting that SK offers an overall protective effect from the damage normally incurred during ischemia.

The present study supports the concept that early thrombolysis will limit infarct size. In fact, the greatest limitation of infarct size determined from HBDH release was observed in patients treated within 2 hours ( $37 \%$ ), whereas the effect of thrombolytic therapy was smaller in those treated between 2 and 4 hours $(13 \%)$. The limitation of infarct size was definitely related to the results of reperfusion (Fig. 2) and to preservation of global and regional left ventricular function as well as to the survival rate. ${ }^{7-9}$ Further studies should compare the relative value of various interventions to establish reperfusion, including intravenous SK, rt-PA or acetylated SK-plasminogen complex, intracoronary administration of these compounds, and immediate percutaneous transluminal coronary angioplasty. Determination of infarct size by means of the methods in the present study will aid in the comparison of such interventions in addition to measurement of left ventricular function and survival.

\section{REFERENCES}

1. Chapman BL: Relation of cardiac complication to SGOT level in acute myocardial infarction. Br Heart J 1972;34:890896.
2. Thompson PL, Fletcher EE, Katavatis V: Enzymatic indices of myocardial necrosis: Influence on short- and long-term prognosis after myocardial infarction. Circulation 1979; 59:113-119.

3. Norris RM, Sammel NL: Predictors of late hospital death in acute myocardial infarction. Prog Cardiovasc Dis 1980; 23:129-140.

4. Grande $P$, Christiansen $C$, Pedersen A: Influence of acute myocardial infarct size on acute and one-year mortality. Eur Heart J 1983;4:20-25.

5. Rentrop P, Blanke H, Koestering K, Karsch KR: Acute myocardial infarction: Intracoronary application of nitroglycerin and streptokinase in combination with transluminal recanalization. Clin Cardiol 1979;2:354-363.

6. Rentrop P, Blanke H, Karsch KR, Rutsch W, Schartl M, Merx W, Dorr R, Mathey D, Kuck K: Changes in left ventricular function after intracoronary streptokinase infusion in clinically evolving myocardial infarction. AM HEART J 1981;102:1188-1193.

7. Simoons ML, Serruys PW, van den Brand M, Bar F, de Zwaan C. Res J, Verheugt FWA, Krauss XH, Remme WJ, Vermeer F, Lubsen J: Improved survival after early thrombolysis in acute myocardial infarction. Lancet 1985;2:578-582.

8. Simoons ML, Serruys PW, van den Brand M, Res J, Verheugt FWA, Krauss XH, Remme WJ, Bar F, de Zwaan C, van der Laarse A, Vermeer F, Lubsen J: Early thrombolysis in acute myocardial infarction: Limitation of infarct size and improved survival. J Am Coll Cardiol 1986;7:717-728.

9. Serruys PW, Simoons ML, Suryapranata H, Vermeer F, Wijns W, van der Brand M, Bar F, Krauss XH, Remme WJ, Res J, Verheugt FWA, van Domburg R, Lubsen J, Hugenholtz PG: Preservation of global and regional ventricular function after early thrombolysis in acute myocardial infarction. J Am Coll Cardiol 1986;7:729-742.

10. Kwong TC, Fitzpatrick PG, Rothbard RL: Activities of some enzymes in serum after therapy with intracoronary streptokinase in acute myocardial infarction. Clin Chem 1984;30:731734.

11. Schroder R, Biamino G, von Leitner ER, Linderer T, Bruggemann T, Heitz J, Vohringer HF, Wegscheider K: Intravenous short-term infusion of streptokinase in acute myocardial infarction. Circulation 1983;67:536-548.

12. Ganz W, Geft I, Maddahi J, Berman D, Charuzi Y, Shah PK, Swan HJC: Nonsurgical reperfusion in evolving myocardial infarction. J Am Coll Cardiol 1983;1:1247-53.

13. Anderson JL, Marshall HW, Bray BE, Lutz JR, Frederick PR, Yanowitz FG, Datz FL, Klausner SC, Hagan AD: A randomized trial of intracoronary streptokinase in the treatment of acute myocardial infarction. $N$ Engl $J$ Med 1983;308:1312-1318.

14. Fioretti P, Simoons ML, Serruys PW, van den Brand M, Fels PW, Hugenholtz PG: Clinical course after attempted thrombolysis in myocardial infarction. Eur Heart J 1982;3:422432 .

15. Zelen M: A new design for randomized clinical trials. N Engl J Med 1979;300:1242-1245.

16. Serruys PW, Wijns W, van den Brand M, Ribeiro V, Fioretti P, Simoons ML, Kooyman CJ, Reiber JHC, Hugenholtz PG: Is transluminal coronary angioplasty mandatory after successful thrombolysis? Br Heart J 1983;50:257-265.

17. van der Laarse A, Hermens WT, Hollaar L, Jol M, Willems GM, Lemmers HEAS, Lieam AH, Souverijn JHM, Oudhof $\mathrm{JH}$, de Hooge J, Buis B, Arntzenius AC: Assessment of myocardial damage in patients with acute myocardial infarction by serial measurement of serum alpha-hydroxybutyrate dehydrogenase levels. AM HEART J 1984;107:248-260.

18. Willems GM, Muijtjes AMM, Lambi FHH, Hermens WT: Estimation of circulatory parameters in patients with acute myocardial infarction. Significance of circulation of enzymatic infarct size. Cardiovasc Res 1979;13:578-587.

19. Witteveen SAGJ, Hermens WT, Hemker HC, Hollaar L: 
Quantitation of enzyme release from infarcted heart muscle. In: de Haas JH, Hemker HC, Snellen HA, editors. Ischemic heart disease. Leiden: University Press, 1970:36-42.

20. Witteveen SAGJ, Hemker HC, Hollaar L, Hermens WT: Quantitation of infarct size in man by means of plasma enzyme levels. Br Heart J 1975;37:795-803.

21. Hermens WT, Willems GM, Visser MP: Quantification of circulating proteins. The Hague: Martinus Nijhoff Publishers, 1982.

22. Willems GM, Dreessen VAB, de Zwaan C, Hermens WT: Estimation of fractional catabolic rates (FCR) of cardiac enzymes in man by multienzyme analysis (abstr). J Mol Cell Cardiol 1984;16(suppl 2):41.

23. Gudbjarnason S, Braasch W, Cowan C, Bing RJ: Metabolism of infarcted heart muscle during tissue repair. Am $\mathbf{J}$ Cardiol $1968 ; 22: 360-369$.

24. Hirzel HO, Sonnenblick EH, Kirk ES: Absence of a lateral border zone of intermediate creatine phosphokinase depletion surrounding a central infarct 24 hours after acute coronary occlusion in the dog. Circ Res 1977;41:673-683.

25. Johnson RN, Sammel NL, Norris RM: Depletion of myocardial creatine kinase, lactate dehydrogenase, myoglobin, and $\mathrm{K}^{+}$after coronary artery ligation in dogs. Cardiovasc Res 1981:15:529-537.

26. Grande P, Fischer Hansen B, Christiansen C, Naestoft J: Estimation of acute myocardial infarct size in man by serum CK-MB measurements. Circulation 1982;65:756-764.

27. van der Laarse A, Davids HA, Hollaar L, Valk EJM, Witteveen SAGJ, Hermens WT: Recognition and quantification of myocardial injury by means of plasma enzyme and isoenzyme activities after cardiac surgery. Br Heart $J$ 1979;41:660-667.

28. Davids HA, Hermens WT, Hollaar L, van der Laarse A, Huysmans HA: Extent of myocardial damage after openheart surgery assessed from serial plasma enzyme levels in either of two periods (1975 and 1980). Br Heart J 1982;47:167172 .

29. Willems GM, van der Veen FH, Huysmans HA, Flameng W, de Meyere $R$, van der Laarse A, van der Vusse GJ, Hermens WT: Enzymatic assessment of myocardial necrosis after cardiac surgery: Differentiation from skeletal muscle damage, hemolysis, and liver injury. AM HEART J 1985:109:12431252.

30. Shell WE, Kjekshus JK, Sobel BE: Quantitative assessment of the extent of myocardial infarction in the conscious dog by means of analysis of serial changes in serum creatine phosphokinase activity. $d$ Clin Invest 1971;50:2614-2625.

31. Roberts R, Henry PD, Sobel BE: An improved basis for enzymatic estimation of infarct size. Circulation 1975;52:743754.
32. Sobel BE: Biochemical and morphologic changes in infarcting myocardium. Hosp Pract 1972;7:59-71.

33. Roberts R, Ishikawa Y: Enzymatic estimation of infarct size during reperfusion. Circulation 1983;68(suppl l):183-189.

34. Tamaki S, Murakami 'I', Kadota K, Kambara H, Yui $Y$, Nakajima H, Suzuki Y, Nohara R, 'Takatsa Y, Kaway $C$, Tamaki N, Mukai T, Torizuka K: Effects of coronary artery reperfusion on relation between creatine Kinase-MB release and infarct size estimated by myocardial emission tomography with thallium-201 in man. A Am Coll Cardiol 1983; 2:1031-1038.

35. Hackel DB, Reimer KA, Ideker RE. Mikat EM, Hartwell TD, Parker CB, Braunwald EB, Buja M, Gold HK, Jaffe AS. Muller JE, Raabe DS, Rude RE, Sobel BE, Stone PH, Roberts $R$, and the MILIS study group: Comparison of enzymatic and anatomic estimates of myocardial infarct size in man. Circulation 1985;70:724-835.

36. Rogers WJ, McDaniel HG, Snith LR, Mantie JA, Russell RO $\mathrm{Jr}$, Rackley CE: Correlation of angiographic estimates of myocardial infarct size and accumulated release of creatine kinase MB isoenzyme in man. Circulation 1977,56:199-205.

37. Morrison J, Coromilas J, Munsey D. Robbins M, Zema M, Chiaramida S, Reiser P, Scherr L: Correlation or radionuclide estimates of myocardial infarction size and release of creatine kinase-MB in man. Circulation 1980;62:277 -287.

38. Geltman EM, Ehsani AA, Campbell MK, Schechtman $K$, Roberts R, Sobel BE: The influence of location and extent of myocardial infarction on long-term dysrhyt hmia and mortality. Circulation 1979;60:805-814.

39. Erhardt LR: Clinical and pathological observations in different types of acute myocardial infarction. Atta Med Scand 1974 (suppl 560):1-78.

40. Shell W, Mickle DK, Swan HJC: Effects of nonsurgical myocardial reperfusion on plasma creatine kinase kinetics in man. AM HEART J 1983;106:665-669.

41. Ong L, Reiser P, Coromilas J, Scherr L. Morrison J: Left ventricular function and rapid release of creatine kinase $M B$ in acute myocardial infarction. Evidence for spontaneous reperfusion. N Engl J Med 1983;309:1-6.

42. Fung AYM, Rabkin SW: Beneficial effect of streptokinase on left ventricular function after myocardial reoxygenation and reperfusion following global ischema in the isolated rabbit heart. J Cardiovasc Pharmacol 1984;6:429-435.

43. Puckett SW, Digerness SB, Bowdon HR, Rogers WJ, Rackley CE: Direct effects of streptokinase on the isolated rat myccardium. J Cardiovasc Pharmacol 1984:6: 1 120-1123. 